\title{
Na bagagem dos peruleros: mercadoria de contrabando e o caminho proibido de São Paulo ao Paraguai na primeira metade do século XVII'
}

\section{José Carlos Vilardaga ${ }^{2}$}

RESUMO: A proposta do presente artigo é analisar alguns bens inventariados em Assunção e no Guairá, na Província do Paraguai, nas primeiras décadas do século XVII, de personagens que saíram de São Paulo rumo aos interiores da América espanhola em demanda de comércio e das riquezas do "espaço peruano", nas partes do Peru. O caminho, que alternava trechos fluviais - Tietê e Paraná - com percursos terrestres, era proibido por Real Cédula desde fins do século XVI, e sua utilização resultou na prisão e no confisco de bens de diversos sujeitos que o utilizaram nas duas direções. Dentre eles, Manoel Pinheiro, mineiro-mor do Brasil, que partiu de São Paulo rumo ao Paraguai, em 1606, e foi preso em Assunção; Manoel Rodrigues, preso em 1620 com vários outros companheiros, todos sem licença; e Miguel Moxica Maldonado, canarino que teve todos os seus bens confiscados no "sertão" do Guairá em 1621. O rol de mercadorias revela o predomínio de tecidos - de variados tipos -, mas também de objetos como facas, tesouras, pentes e contaria, e algumas peças de ouro. Pretendemos compreender esses objetos da cultura material - aqui vistos como mercadorias em processo de circulação - como elementos constitutivos de uma espacialidade conectada luso-castelhana na América Meridional, como articuladores de relações sociais e hierarquias, e parte das redes de intercâmbio estabelecidas entre a Capitania de São Vicente e a Província do Paraguai em tempos de União das Coroas Ibéricas.

PALAVRAS-CHAVE: História conectada. Mercadoria. Cultura material. América Colonial. Caminho de São Paulo.

ABSTRACT: The purpose of this article is to analyze some goods inventoried in Asunción and in Guairá, in the Provincia do Paraguai, during the first decades of the 17th century, of characters who left Sao Paulo for the interior of Spanish America in demand of commerce and riches of the "Peruvian space" in parts of Peru. The route, which alternated between river stretches - Tietê and Paraná - and land routes, was prohibited by Real Cédula from the end of the 16 th century

\begin{abstract}
1. Este texto faz parte da pesquisa Fluxos, intercâmbios e circulação na região platina - séculos XVI e XVII, desenvolvida com financiamento do CNPq/Universal (2014).

2. Doutor em História pela Universidade de São Paulo (USP). Professor no Departamento de História na EFLCH-Unifesp. E-mail: <jvilardaga@unifesp.br>.
\end{abstract}


3. Os termos "partes do Peru" ou "bandas do Peru" são muito comuns na documentação coeva e têm sobretudo um sentido genérico, tanto em termos administrativos, quanto no imaginário coletivo, abarcando um amplo território colonial castelhano da América do Sul. Ver Ventura (2005).

4. Os debates no campo da Geografia em torno das definições de "espaço" e "território" são inúmeros. O termo espaço - polissêmico - associa-se sobretudo a uma noção, por isso mesmo menos preciso que o território, que é um conceito, mais formal e correspondente, em geral, a um momento posterior do espaço, no qual o Estado ou as instituições atuam numa lógica mais demarcatória e de dominação política. Raffestin (1993). Ademais, não devemos separar o espaço natural do social, compreendendo-o não como algo dado a priori, nem como mero palco das interações entre a sociedade e a natureza, mas como um criador de realidades. Moraes (2000), Santos (2006).

5. Serge (2014).

6. Depois de 1618 a Província do Paraguai e a Província do Rio da Prata foram separadas. and its use resulted in the arrest and confiscation of goods of several people who used it in both directions. Among them, Manoel Pinheiro, miner-mor of Brasil, who left Sao Paulo for Paraguai in 1606 and was arrested in Asunción; Manoel Rodrigues, imprisoned in 1620 with several other companions, all without a license; and Miguel Moxica Maldonado, a Canarian who had all his goods confiscated in the "sertão" (backwoods) of the Guairá in 1621. The list of goods reveals the predominance of fabrics - of various types - but also of varied objects such as knives, scissors, combs and counters, and some gold pieces. We intend to understand these objects of material culture - seen here as commodities in the process of circulation - as constitutive elements of a connected Luso-Castilian spatiality in South America, as articulators of social relations and hierarchies, and part of the exchange networks established between the Capitania de São Vicente and the Provincia do Paraguai in times of Union of the Iberian Crowns.

KEYWORDS: Connected History. Goods. Material culture. Colonial America. São Paulo route.

Neste artigo pretendemos traçar um mapeamento inicial do tipo de mercadoria que fazia parte da bagagem dos chamados peruleros, personagens que atravessavam os caminhos interiores da América Meridional rumo às "partes do Peru", expressão geográfica por si só bastante ampla e imprecisa. ${ }^{3}$ Esses peruleros, dos quais aqui tratamos, transpunham as jurisdições portuguesas e castelhanas e, por isso mesmo, podem ser compreendidos como sujeitos transfronteiriços e importantes agentes de uma história conectada luso-castelhana na América.

$\bigcirc$ período aqui trabalhado, qual seja, o chamado contexto da União das Coroas Ibéricas (1580-1640), é, por razões óbvias, propício para se falar de conexões luso-castelhanas. Contudo, tal perspectiva não pode ser naturalizada, e apenas desvelar esses intercâmbios não se mostra suficiente. $\bigcirc$ fundamental, aqui, é entender como se organizaram espacialidades coloniais - para além das jurisdições formais - articuladas a essas conexões. Ademais, devemos sublinhar o papel dos objetos que, relacionados intrinsicamente aos sujeitos que circulavam por esses espaços, ajudaram a conformar relações sociais, estabelecer alianças, e participaram da conformação de um território colonial, dando-lhe um determinado sentido numa temporalidade e conjuntura específicas. ${ }^{4}$

Os objetos que serão analisados neste artigo foram fundamentais, portanto, para a configuração de uma espacialidade que é basicamente regional, mas inserida no amplo espaço imperial conectado, posto em movimento pela Monarquia católica sob a liderança dos Habsburgo. ${ }^{5}$ Esse espaço, intermediário e substanciado na circulação de pessoas e objetos, concretiza-se, neste trabalho, numa geografia que articulava a vila de São Paulo de Piratininga, na Capitania de São Vicente, partes do Brasil, com o Guairá e Assunção, partes da Província do Paraguai e Rio da Prata, Vice-Reino do Peru. ${ }^{6}$ Devemos entender que nesses espaços se 
articularam diversos grupos, comunidades, vilas e cidades através dos sujeitos e seus objetos, aqui postos em relevo através de um breve arrolamento de mercadorias apreendidas em processos documentados na Província do Paraguai.

Ressalte-se que compreendemos mercadoria como um "fenômeno cultural universal", pois é através dela que os mais diversos grupos sociais e culturas, em distintas temporalidades, promovem intercâmbios. $\bigcirc$ que diferencia uma das outras é a forma pela qual estruturam essa mercantilização e as posturas culturais e ideológicas em jogo. ${ }^{7}$ A mediação, ou não, do dinheiro nas trocas não altera o sentido mercantil de determinado objeto. De fato, a mercantilização é apenas uma parte de sua trajetória, mas é exatamente sobre ela que pretendemos nos deter. Assim, buscamos compreender determinados objetos em sua "situação mercantil", 8 e como parte de uma "economia substantiva", na qual as relações econômicas são perpassadas pelas relações sociais e culturais. ${ }^{9}$ Importante frisar, contudo, que considerarmos a mercadoria como um fenômeno universal não significa que a tomamos como absoluta. Ao contrário, buscamos ressaltar a particularidade e o dinamismo das relações mercantis, evidentes a partir da condição transitória e contextual que a trajetória de determinado objeto apresenta como mercadoria. ${ }^{10}$

Além disso, abordar a mercantilização de um objeto é também falar de circulação e valor. Durante muito tempo predominou uma visão que atribuía valor a uma mercadoria essencialmente a partir da produção e, quando muito, de uma variável posta em cena pelo jogo econômico da oferta e da demanda. Sem negar ambas as atribuições, é fundamental entender que o valor de um objeto é também dado pela sua condição na rede de trocas e pelo seu contexto. Como afirma Appadurai, não é o valor que define a troca como algo exógeno, mas é a capacidade de troca numa rede de relações essencialmente contextual - econômica, social, cultural, política - que define o valor. Os valores se criam - ou se transformam - no universo relacional no qual se inserem. " Qualquer objeto está sujeito à mercantilização - ressalvando que aqui não pretendemos separar de modo estrito a noção de mercadoria e de giff-, e seu sentido é dado tanto pelo que ele representa enquanto signo, quanto pelo que ele tem de funcional, material e de elemento constitutivo da realidade social. ${ }^{12}$ Dessa forma, os agentes responsáveis pela circulação dessas mercadorias, em alguns casos, comerciantes, não devem ser vistos apenas como agentes econômicos, mas também como intermediários culturais e como personagens essenciais na construção e reiteração de valores, hierarquias e também de desigualdades sociais, postas em cena pela posse de objetos.

espaço ${ }^{13}$ e os caminhos

Como ponto de partida dessa análise, deve-se apresentar melhor a espacialidade aqui tratada e em grande parte organizada a partir da circulação de pessoas e objetos. Inicialmente, numa perspectiva ampliada, pensamos numa conexão que atrela a Capitania de São Vicente (e também a do Rio de Janeiro) ao
7. Kopytoff (2009).

8. Appadurai (2009).

9. Para a noção de "economia substantiva", ver Polanyi (2012).

10. Quem nos alerta para essa questão é Rede (2001).

11. Appadurai (2009).

12. Tanto Appadurai (2009) quanto Miller (2013) buscam esse cruzamento entre a clássica noção de gift (dádiva), elaborada por Marcel Mauss, e a noção de mercadoria e as teorias do consumo.

13. Como já apontamos, analisaremos aqui um espaço que se constrói nas redes de relações e na circulação de pessoas e objetos, antecedendo e mesmo ultrapassando as tentativas de regulação territorial estabelecidas pelas jurisdições coloniais. 
14. Percebemos o contrabando como uma prática que compreendia a circulação tanto de pessoas quanto de mercadorias por caminhos e locais que eram parcialmente vetados por um conjunto de normas, bandos ou cédulas. A ilegalidade poderia recair sobre os sujeitos ou sobre os objetos, mas tanto uma aparente aleatoriedade dos processos quanto o conteúdo dos julgamentos reforçam a noção de que a repressão ao contrabando tinha muito mais a ver com o quem, do que com o quê (Pijning, 2001). De toda forma, na perspectiva comercial, compactuamos com a ideia que enxerga o contrabando como parte intrínseca da lógica mercantil colonial, sendo uma outra forma de acumulação de lucros e marcada pelas rivalidades e disputas entre redes e grupos mercantis. Moutoukias (1998) e Cavalcante (2006).

15. A noção de "espaço peruano" foi elaborada por Assadourian (1983) e propõe a compreensão de uma amplíssima espacialidade articulada de diversas maneiras - nem sempre diretas - com o centro minerador do Alto Peru.

16. A respeito de uma análise pormenorizada do Caminho Real e os mecanismos legais e ilegais de comércio praticados a partir de Buenos Aires e ao longo da via, ver Moutoukias (1988), Assadourian (1983), Perusset (2006), González Lebrero (2002), Vilardaga (2015).

17. Canabrava (1984). espaço platino, tanto a partir do litoral Atlântico quanto pelas vias fluviais e terrestres do interior. A região platina aqui referida era formada pelas Províncias do Paraguai, Rio da Prata e Tucumã, território de amplíssima circulação, oficial e de contrabando, ${ }^{14}$ que em última instância compunha o que certa historiografia conceituou como "espaço pervano". ${ }^{15}$ Estruturado pelo chamado Caminho Real que ligava o porto de Buenos Aires a Potosí, ele passava pelas cidades de Córdoba, Santiago de Estero, São Miguel de Tucumã, Salta e Jujui, chegando até o núcleo potosino da prata, no Alto Peru. Um de seus ramais desdobrava-se por San Juan até Santiago do Chile e outro por Santa Fé, subia o Paraguai até Assunção. Era percorrido no seu eixo principal pelas famosas carretas de Tucumã, puxadas por bois e inteiramente feitas de madeira, as quais transportavam produtos do circuito legal e ilegal, como chapéus, tecidos diversos, escravos negros, prata, ouro, erva-mate, vinhos, ferramentas, objetos variados, sementes e produtos vindos da Europa. ${ }^{16}$ Cumpria tanto uma lógica transatlântica quanto regional, atrelando os destinos do espaço peruano ao espaço atlântico. O litoral do Brasil, em especial as praças portuárias de São Vicente, Rio de Janeiro, Salvador e Olinda, participava desse negócio platino desde o final do século XVI com mercadorias como açúcar, ferro, escravos, marmeladas e outros produtos. ${ }^{17}$ Tais conexões foram tributárias do esforço do "bispo-mercador" de Tucumã, Francisco de Vitória, um português que vislumbrou muito cedo as potencialidades dos intercâmbios com a costa do Brasil.

Menos volumoso e menos analisado do que o circuito hegemônico atlântico, que se prolongava territorialmente pelo Caminho Real, um outro caminho interior conectava o litoral da Capitania de São Vicente, mas mais especialmente a hinterland do planalto, onde ficava a vila de São Paulo de Piratininga, com a Província do Paraguai por vias majoritariamente fluviais. $\bigcirc$ rio Tietê, navegável em grande medida rumo ao rio Paraná, compunha-se de caminho natural. Essa contiguidade espacial entre o que viria a ser a Capitania de São Vicente e a Província do Paraguai não se deve estranhar, pois os contemporâneos já assim a percebiam.

O almirante asturiano Diego Flores Valdés, que pela Capitania passou em missão ao Estreito de Magalhães em 1583-84, sugeriu a Felipe Il que tomasse posse de São Vicente, vislumbrando as relações com o interior castelhano; o criollo Hernandarias de Saavedra, três vezes governador da Província do Paraguai e Rio da Prata, primeiro sugeriu a anexação da Capitania vicentina às províncias platinas, mas depois terminou por solicitar o despovoamento de São Paulo frente à ameaça das entradas dos moradores de Piratininga; o vice-rei do Peru, Marques de Montes Claros, em 1610, sugeriu que São Paulo fizesse parte da futura Província do Paraguai, a ser desmembrada do Rio da Prata; e o Conde de Chinchón, também vice-rei do Peru, em 1630, pleiteou que o rei comprasse a Capitania de São Vicente que pertencia ao donatário.

O território compreendido pelas duas governações formou, gradativamente, um mercado regional transfronteiriço no qual a circulação de pessoas e mercadorias foi intensa. Este é um ponto de partida importante para a 
análise, pois certa imagem da historiografia, especialmente produzida pelos paulistas, reiterou visões tradicionais sobre esse interior como uma no man's land; um sertão bravio e aventuroso, palco de bandeirantes alargadores da fronteira pátria. ${ }^{18}$ A essa visão, mas em menor escala, somou-se uma que concebia esses espaços como um corredor de passagem utilizado por peruleiros sazonais que buscavam o Peru por um caminho essencialmente difícil, perigoso e insólito. Essa imagem esteve presente ainda no século XVII, em parecer do licenciado Antonio de Leon y Pinelo que, em defesa da licença de comércio pelo caminho portenho como única solução para a Província, produziu um texto no qual afirmava que a via existente entre São Paulo e o Paraguai era comparável à de Castela e Aragão em termos de dimensão, mas à de Castela e Norvega em termos de obstáculos e dificuldades. Dizia ele que "no se hallará quien aya tocado semejante viagen, ni dicho que por el ayab ido jamas mercaderias [... son casi 400 leguas de despoblado". ${ }^{19}$

A análise detida desse caminho, empreendida a partir de uma documentação bastante variável, tem demonstrado o oposto. Mesmo que menos volumosa, a circulação por aquele caminho foi bastante regular e importante na ocupação colonial e na gradativa conformação territorial das áreas luso-castelhanas na região platina. As possibilidades de uso e usufruto do caminho foram especialmente férteis nas primeiras décadas do século XVII; mas isso não significa que na segunda metade do século XVI, depois dos primeiros assentamentos coloniais luso-castelhanos terem se consolidado, e após 1630, com os ataques bandeirantes à região, o caminho não tenha sido também utilizado - pelo contrário, ele o foi. ${ }^{20}$ Contudo, entendemos que esse período em especial, pela conjuntura mesma da União das Coroas, e por sua confusa situação jurisdicional, foi uma "janela" decisiva para definir relacionamentos e estruturar caminhos entre esses dois territórios coloniais. E nela, a ocupação dos espaços e sua articulação a partir dos caminhos percorridos por sujeitos e seus objetos jogaram um peso decisivo.

A documentação é imprecisa, infelizmente, em termos de definição sobre a materialidade dos meios de transporte e dos caminhos. Por onde se ia e como se ia? $\bigcirc$ governador do Paraguai, Luis de Céspedes e Xeria, produziu o único relato pormenorizado do trajeto, feito, por ele, em canoas, pelo Tietê, em 16 dias. ${ }^{21}$ Manuel de Frias, também governador do Paraguai, em carta, dizia que tal trajeto se podia fazer em 15 ou 20 dias. ${ }^{22}$ A documentação deixa antever, aqui e ali, a presença de canoas e o termo "navegação" quando se refere ao caminho, ou via, "proibida de São Paulo". Imagina-se que se alternassem formas de transporte fluvial e terrestre, seguindo, basicamente, as trilhas e experiências indígenas, e esta é uma questão de grande importância. ${ }^{23}$ Devemos assumir como princípio basilar dessa análise que os percursos coloniais se fizeram, sobretudo, sobre caminhos indígenas pré-hispânicos secularmente percorridos por diversos povos e etnias. A experiência dos índios a respeito dessas trilhas e espaços, que articulavam esse território desde muito antes da chegada dos europeus - já tão brilhantemente analisada por Sérgio Buarque de Holanda - cumpriu um papel decisivo na forma
18. Pensamos aqui essencialmente numa historiografia que exaltou a figura do bandeirante, como Afonso Taunay, Alfredo Ellis, Ernani da Silva Bruno, dentre outros. A respeito do caminho de São Paulo ao Paraguai, a percepção das autoridades coloniais, e uma análise da circulação por aquela via, ver Vilardaga (2014).

19. Petição (s.d.).

20. Sobre o uso desse caminho antes do século XVII, ver Holanda (1948).

21. Arquivo General de Indias (AGI), Fundo Mapas y Planos - Buenos Aires (17, 1,1, s.d.).

22. Dabbs (1959).

23. Moura (1908) foi o responsável por empreender uma das primeiras tentativas para esboçar efetivamente os locais do trajeto e os meios de locomoção pelo caminho. 
24. Holanda (1994). O mesmo autor (2014) promove, em outra obra, no capítulo "O transporte fluvial", um enriquecedor estudo de cultura material em torno do uso de canoas, balsas e outras embarcações pelos rios da Bacia do Prata e rios da América portuguesa.

25. Uma das primeiras proibições de entrada e comércio de portugueses no Peru data de 1594, através de uma cédula real. Uma outra, de 1602 , ordenava a expulsão dos estrangeiros estabelecidos sem licença nas colônias, em especial os portugueses entrados pelo Rio da Prata.

26. Os irmãos Fernandes possuíam muitos vínculos com o Paraguai. Um dos irmãos - Domingos - casou-se com uma hispano-paraguaia do Guairá, e eles acolheram diversos moradores da região em Santana de Parnaíba na primeira metade do século XVII. André frequentou o Guairá inúmeras vezes e escoltou D. Victoria de Sá, mulher do governador paraguaio Céspedes e Xeria, até Assunção. Um de seus filhos foi ordenado na capital assuncenha. Para uma descrição breve desses vínculos, ver Franco (1954), Garcia (1956), Ferreira (1971) e Vilardaga (2014).

27. Reis (2013). pela qual os caminhos foram incorporados e transformados conforme as novas relações estabelecidas pela situação colonial. ${ }^{24}$ Ademais, os grupos indígenas eram uma presença constante ao longo de todo o trajeto, mesmo que muitas vezes silenciada na documentação. Enxergá-los significa perceber, aqui e ali, referências a eles como guias, carregadores, remadores, fornecedores de abrigo, alimentos e auxílio, bem como partícipes do universo de trocas mercantis e relações estabelecido no caminho.

De todo modo, a via, que ficou conhecida como o camino proibido de San Pablo nos processos movidos contra seus usuários no Paraguai, chamou a atenção das autoridades peninsulares e coloniais, como a existência mesma desses processos denota. A tentativa de regulação dessa rota acompanhou as iniciativas de controle sobre todos os caminhos coloniais que, de alguma forma, permitiam em última instância acessar as preciosas minas de Potosí. Dessa maneira, ser pego sem licença pessoal emitida pela Casa de Contratação, ou carregando mercadoria proibida, era considerado crime tanto na via de São Paulo quanto na de Buenos Aires ou de Cartagena. ${ }^{25}$ Muitos foram os encarcerados, outros afiançados, e mais alguns evadidos, mas, no final, a esmagadora maioria acabou sendo anistiada. Destes, uma parte se dirigiu para outras localidades da América e outra integrou-se às comunidades nas quais haviam sido presos.

Para apresentar o caminho, esboçamos agora uma espécie de retrato da via no período compreendido entre 1600-1630. É uma aproximação em relação aos locais e trajetos atravessados pela rota. Imaginando que alguém partisse de São Paulo de Piratininga rumo oeste, encontraria inicialmente alguns aldeamentos indígenas, em especial o de Barveri, criado em 1609 pelo governador-geral D. Francisco de Souza; e o de Carapicuíba, inicialmente posse de um rico morador, Afonso Sardinha, que em 1616 foi legado em herança aos jesuítas. O objetivo dessas reduções - aqui chamadas de aldeamentos - era abrigar índios descidos do "sertão" pelas bandeiras, para dali serem repartidos nos trabalhos agrícolas e minerais alavancados pelo governador. Um pouco mais adiante, a freguesia de Santana de Parnaíba - tornada vila em 1625 - era um importante núcleo de ocupação, no qual os irmãos Fernandes - André, Baltazar e Domingos -, potentados locais, travariam significativas e decisivas relações com o Paraguai. ${ }^{26}$ Ademais, ali existiam minas de ouro, de onde se extraíram quantidades ainda de difícil aferição. ${ }^{27}$ Descendo um pouco mais ao sul, seguindo por um ramal fluvial, chegava-se à vila de São Filipe - de localização precisa ainda desconhecida. Essa vila, estrategicamente situada nas redondezas das desejadas minas de ouro e ferro conhecidas como Araçoiaba, fora também criada a mando do governador D. Francisco de Souza, e recebeu o nome dos monarcas Habsburgo. A vila, pelo que se sabe, teve vida curta. Seguindo mais a oeste, chegava-se ao porto de Pirapitingui, provavelmente o ponto no qual era possível iniciar a navegação pelo rio Tietê. O lugar aparece nas atas da Câmara como local no qual os índios vindos do sertão pelo rio trocavam mercadorias. Clemente Álvares, morador da vila de São Paulo, costumava ali montar sua tenda de ferreiro para resgatar com os 
índios. ${ }^{28}$ A partir dali as canoas seguiam pelo rio até o Paraná ou seus afluentes guairenhos, como o Paranapanema, Tibagi, Ivaí e lguaçu. Algumas das pessoas que pelo caminho seguiam faziam-no por conta própria, outras contratavam guias, como os irmãos Godoy de São Paulo que, em troca de algum dinheiro e roupas, levavam interessados até o Salto do lguaçu. ${ }^{29}$

Chegando ao chamado Guairá, espaço também bastante impreciso em termos de demarcação, acessava-se um arco de três cidades castelhanas. ${ }^{30}$ Ao norte, em território hoje situado no Mato Grosso do Sul, nas proximidades do rio Miranda, estava a vila de Santiago de Jerez, trasladada uma terceira vez pelo criollo e mestizo assuncenho Ruy Diaz de Guzmán em 1599. A vila dava sustentação às encomiendas sobre os índios chamados de ltatim. Descendo pelo rio Paraná, próximo ao Salto, estava a vila castelhana mais antiga da região, Ciudad Real del Guairá, nascida em 1557 depois do despovoamento da efêmera vila de Ontiveros. ${ }^{31} \mathrm{Na}$ confluência dos rios Corumbataí com Ivaí estava localizada a vila que teve o destino mais próspero de todas: Vila Rica do Espírito Santo. Conhecida como cidade andariega, teve sete localizações distintas ao longo da história. A que tratamos aqui é a segunda, mandada trasladar-se também por Rui Diaz de Guzmán em 1589. ${ }^{32}$ A região ainda contava com diversos pueblos de índios, dos quais extraía-se o grosso dos indígenas das encomendas regionais, e pelo menos 12 reduções jesuíticas. As duas primeiras - Nossa Senhora de Pirapó e lguaçu - foram criadas em 1610, e as outras dez entre 1622 e 1625. As reduções do Guairá foram das primeiras - e mais decisivas - experiências missionárias dos jesuítas na América. Estas, em especial, tiveram curta duração e parco desenvolvimento urbano e arquitetônico, mas a experiência acumulada ali seria fundamental para informar as amplíssimas missões que compuseram o cenário dos chamados Trinta Povos da Missões nos séculos XVII e XVIII. ${ }^{33}$ As reduções do Guairá pontuavam o espaço regional e se articularam numa rede fluvial que atraía muitos indígenas e, com isso, a fúria dos encomenderos e dos bandeirantes paulistas.

Na direção sudeste de Vila Rica ficava uma mina de ferro chamada de Tambó, de onde se extraía o minério que permitia a fundição das cunhas (cuñas), importante moeda local e objeto bastante desejado pelos indígenas. Algumas vezes - lugar era também identificado como um pueblo, ou corregimiento. Depois do rio Paraná, no sentido de Assunção, ficava o Porto de Mbacarayú, próximo à nascente do rio Jejui-Guazú. Importante ponto comercial, ali se concentrava a erva-mate extraída da Serra de Mbaracayú, um pouco mais ao norte. $\bigcirc$ lugar reunia tratantes e mercadores, indígenas, balseiros e autoridades coloniais. Dali as embarcações com a erva, já torrada e moída, seguiam, em sua maioria, rumo a Assunção para então espraiarem-se pelas rotas platinas, tucumenhas e alto-peruanas. ${ }^{34}$

A apresentação desses pontos demonstra cabalmente que estamos diante de uma região bastante ocupada, dinâmica e articulada, o que contraria uma visão ainda hegemônica desse interior americano percebido como sertão bravio e vazio, cenário de aventurosas expedições bandeirantes. Nesse espaço,
28. Atas (1610). O termo resgate é amplamente utilizado na documentação coeva. Para Raphael Bluteau, dentre seus significados está o de comutar, trocar, substituir. É continuamente associado às trocas com os indígenas, envolvendo ou não prisioneiros e escravos.

29. Arquivo Nacional de Asunción (ANA) (Seção História, Vol. 36, n. 22, s.d.). Nesse processo, os quatro portugueses presos testemunharam que os mancebos Godoy, de São Paulo, guiavam os viajantes até o Salto do Iguaçu em troca de "ropas y patacones".

30. Cardozo (1938), um dos primeiros historiadores a trabalharem com o Guairá, esboçou uma demarcação desse território que sugeria o rio Paraná a oeste, o rio Iguaçu ao sul, o rio Paranapanema ao norte e um vago Tratado de Tordesilhas a leste. Entendemos que as fronteiras são mais fluidas e instáveis, pois ora se encaixam nos limites sugeridos por Cardozo, ora extravasam. De todo modo, apesar de Santiago de Jerez estar nominalmente em outra jurisdição (Nova Vizcaya, e depois Nova Andaluzia), deve ser concebida como parte desse amplo arco de ocupação colonial.

31. A vila de Ciudad Real foi fundada em 1557 por Rui Diaz de Melgarejo, com a transferência dos moradores da cidade de Ontiveros, que fora criada em 1554 por Garcia de Vergara nas margens do rio Paraná.

32. A primeira Vila Rica foi fundada em 1570 por Rui Diaz de Melgarejo.

33. Armemi (1996), Quarleri (2009).

34. Sobre a erva-mate, ver Garavaglia (2008). 
35. Santos (2006, p. 38).

36. Santos (2006, p. 225).

37. Santos (2006).

38. Fernand Braudel (1957, p. 57) apud Santos (2006, p. 210).

39. Utilizamos aqui o termo tratante, pois ele é o mais recorrente na documentação castelhana.

40. A pesquisa atual tem permitido aprofundar e conhecer mais personagens desse trânsito. pessoas e objetos participaram de percursos, trocas e alianças, dando um sentido fundamental a essa rede de vilas, cidades, pueblos, reduções, portos e aldeias. Milton Santos compreendia o espaço como um "conjunto de fixos e fluxos", que se relacionam dinamicamente alterando tanto a fixidez dos pontos quanto a lógica dos fluxos. ${ }^{35}$ De todo modo, estamos a pensar num espaço - distinto de mera configuração territorial - definido, ainda na lição de Santos, como um "conjunto indissociável de sistemas de objetos e de sistemas de ações". ${ }^{36}$ Nos pontos organizados para e pelos fluxos, objetos, sujeitos e ações dão sentido a um espaço que nunca é neutro, mas organizado pelo homem na interação com a natureza. Assim, longe de enxergar esse espaço como algo dado, estável e definido, devemos compreendê-lo em sua dinâmica, elaboração e estruturação. E aqui, novamente, a circulação cumpre um papel-chave, já que o valor de determinado espaço também é dado pela densidade, relevância e quantificação do que circula por ele. ${ }^{37}$

Nesses espaços formam-se, e atuam, por exemplo, redes de comércio que se articulam a outras redes mais ou menos regionais ou globais, ainda mais no contexto sobre o qual nos debruçamos, qual seja, de formação do mercado global na lógica de estruturação do capitalismo moderno. Por mais particular e regionalizado que seja esse pequeno espaço de circulação aqui tratado, comungamos da ideia de que através dele pode-se descobrir muito sobre o movimento global, pois todos são, nesse contexto, "contemporâneos e sincronizados; eles coexistem, estão misturados e somam ou subtraem seus movimentos diante das oscilações do conjunto". 38

Tratantes, ${ }^{39}$ aventureiros e bandeirantes

Não é o objetivo aqui tratar longamente das pessoas que percorriam a "via proibida" de São Paulo, em ambos os sentidos. Contudo, para uma análise apropriada dos objetos que acompanhavam as pessoas, é fundamental caracterizarmos em algumas linhas essas personagens. Inicialmente, ressalte-se que o material documental utilizado para traçar esse perfil é bastante amplo e diversificado. O Arquivo Nacional de Assunção (ANA) nos informa com processos judiciais contra "clandestinos" censos populacionais e perdões reais. A documentação paulista, composta por Inventários e Testamentos, Datas de Chão, Atas e Registros da Câmara, também nos auxilia a montar parte desse quebra-cabeça que reúne fragmentos esparsos em múltiplos lugares que, à primeira vista, foram percebidos como apartados. Levantamos, como maior ou menor qualidade de informação, algo em torno de 120 nomes, compostos por portugueses, açorianos, castelhanos, canarinos e mesmo flamengos. ${ }^{40}$ São tipos variados, com objetivos e intenções distintas, mas uma parte significativa deles assentou moradia, acordou casamento e tornou-se tratante em algum dos pontos do trajeto, reiterando o que já afirmamos aqui: que o espaço tinha também 
valor em si mesmo, pelos seus fixos, e não somente pelos seus fluxos, como zona de passagem para o mirífico Peru.

Às vezes, motivos prosaicos são apresentados, como o de Sebastian Garcia, que foi a São Paulo desde Vila Rica, alegando que iria participar de um casamento. Usuário de canoas para o deslocamento, o processo sobre ele tenta apurar por que foi acompanhado de um grupo de indígenas e voltou sem ele. Pior, pois trouxe nas vagas liberadas alguns clandestinos. ${ }^{41}$ Outro vilarriquenho, Francisco Benitez, era assíduo frequentador do caminho. A primeira vez que foi a São Paulo, também desde Vila Rica, foi em 1603, quando levou consigo vinho e mercadorias para trocar no planalto de Piratininga. Tratou casamento com uma família castelhana de São Paulo, mas no final o enlace não vingou. Isso não o afastou da vila paulista, pois foi acusado na década de 1610 de trazer "clandestinos" pela via; na década de 1620 de facilitar a vida de bandeirantes que avançavam pelo Guairá, e na década de 1630 de ser garoto de recados do governador Céspedes e Xeria, trocando mensagens entre as duas vilas. ${ }^{42}$

Dentre os chamados "clandestinos" havia padres, como o filho de André Fernandes, de Santana de Parnaíba, que se ordenou em Assunção, e Juan Medina del Campo, natural de Ciudad Real, que se tornou cura em Parnaíba. Além desses, outros frades, franciscanos, antoninos e ermitões que, sem nome, são apresentados como proibidos e fugitivos. Um deles armou um plano de fuga com indígenas, que o esperaram fora da prisão em Assunção com canoas. Foi bem-sucedido! Um certo padre Bayeta, de Assunção, foi acusado de acobertar proibidos e facilitar sua fuga pelos caminhos que levavam a Tucumã. ${ }^{43}$

A esmagadora maioria era composta por homens, mas mulheres, como Isabel Correia e sua filha Catarina da Silva, fizeram o caminho rumo ao Guairá; assim como Vitória de Sá, que percorreu o trajeto acompanhada de seu primo Salvador Correia de Sá e Benevides, em 1630, para encontrar seu marido, o governador do Paraguai, Luis de Céspedes e Xeria. Há aventureiros como Enrique Vaz, platero, chamado de embustero, que foi sozinho de São Paulo a Vila Rica. Dormiu clandestinamente nas minas de Tambó, onde fundiu algum metal, e partiu para Potosí, lugar no qual não foi agraciado pela sorte, sendo obrigado a retornar ao Paraguai, mais especialmente à Assunção, para tornar-se boticário.

Por fim, encontram-se diversos tratantes, a maior parte deles envolvida com negócios da erva-mate. Juan Nunes Cardoso, nesse sentido, é um exemplo riquíssimo. Além de ter negócios com o mate em Mbaracayú, onde permanecia parte do ano, era casado em Assunção e apareceu pelo menos uma vez vendendo mercadorias em São Paulo, que registrou na Câmara. ${ }^{44}$ De alguma forma, a geografia percorrida por Cardoso expressa o universo de conexões desde espaço de que aqui tratamos. Dentre esses tratantes, homens que podem ser chamados de bandeirantes, como Nicolau Machado, que fez parte da bandeira de Nicolau Barreto e se perdeu mais tarde pelos caminhos alto-peruanos; e Jerônimo da Veiga, minerador de ouro nas terras dos Guarulhos e que foi preso em Assunção com cestas de erva-mate. ${ }^{45}$ Veiga mostra como as bandeiras deveriam cumprir funções
41. ANA (Seção Civil y Judicial, vol. 1800, n. 3, Ano 1607).

42. Para acompanhar a trajetória de Francisco Benitez: ANA (Seção Historia, vol. 36, n. 23, s.d.); Anais (1922, p. 318-353); Cortesão (1951, p. 389-398).

43. ANA (Seção Civil y Judicial, vol. 1532, n. 33).

44. ANA (Seção Nova Encadernação, vol. 360, s.d.); Registro (24 jul. 1638).

45. Sobre Nicolau Machado, ANA (Seção Historia, vol. 36, n. 23, s.d.); e sobre a prisão de Jerônimo da Veiga no Paraguai, ver ANA (Seção Civil y Judicial, vol. 1549). 
46. ANA (Seção Civil y Judicial, vol. 1685, n. 2, ano 1613).

47. ANA (Civil y Judicial, vol. 1549 , n. 4).

48. Registro (21 jul. 1608).

49. AGI, Fundo Contaduria, vol. 1690).

50. ANA (Seção Civil y Judicial, vol. 1944, n. 4, ano 1609). mais diversificadas do que o apresamento indígena e busca de ouro. Num interessante processo criminal de Assunção, o vilarriquenho António Cardoso acusou as autoridades e "soldados" de Vila Rica de aceitarem suborno dos "portugueses de San Pablo" - bandeirantes - que compravam a cumplicidade com vestidos que levaram consigo. ${ }^{46}$

Ao somarmos a essa função de suborno dos tecidos o fato de os irmãos Godoy, de São Paulo, cobrarem também em roupas o serviço de guia pelos caminhos do sertão, teremos aqui uma primeira aproximação diante de um tipo de objeto - o tecido e suas múltiplas variações - que circulava por aquelas vias proibidas. Para conhecermos com mais detalhes esses objetos, entraremos na bagagem de algumas das personagens aprisionadas no caminho e que tiveram sua carga inventariada e apreendida. Trata-se de uma pequena amostragem que pode nos apontar algumas direções.

As coisas

Analisaremos aqui três processos guardados no Arquivo de Assunção. Para tanto, é necessária a realização de uma breve apresentação de cada um deles e, em seguida, uma análise em bloco. $O$ primeiro trata da prisão e confisco dos bens, em 1606, de Manoel Pinheiro Azurara, que foi mineiro-mor do Brasil. ${ }^{47}$ Azurara teria vivido em Nova Granada com sua família até a década de 1590, quando foi atraído ao Brasil pelo governador D. Francisco de Souza, que perseguia objetivos minerais em diversos locais da Colônia. Era especialista em ouro, e acabou se dirigindo a São Paulo, onde participou ativamente de alguns dos empreendimentos do governador na Capitania de São Vicente. Esteve em Lisboa, Madri e Valladolid entre 1602 e 1603, dando conta das descobertas minerais feitas em solo vicentino e solicitando mercês. Voltou da Corte com o ofício de mineiro-mor e uma autorização para voltar a Nova Granada depois de três anos de exercício da função. Carregava consigo, para imediata aplicação, o Regimento Mineral de 1603. Voltou a São Paulo, distribuiu datas minerais e, em 1605, pediu autorização à Câmara da vila para buscar sua família. ${ }^{48}$ Resolveu chegar à Nova Granada pelo Paraguai! Deixou para trás uma casa ao lado da Sé e partiu pelo interior. Passou por Vila Rica do Espírito Santo, onde teve um seu escravo negro - um jovem de 17 anos chamado Anton -, que o acompanhava, confiscado e leiloado. Ele mesmo o arrematou de volta. Nessa ocasião estava acompanhado de Pedro Ribeiro, que também teve um escravo confiscado e leiloado. ${ }^{49}$

Dali, Pinheiro seguiu para Ciudad Real e finalmente a Mbaracayú, sempre trocando tecido, que carregava consigo, por cestas de erva-mate, a principal riqueza regional. Sabemos dessas trocas pois, em 1609, Pinheiro ainda cobrava essas dívidas. ${ }^{50}$ Além de minerador, fazia tratos. Uma de suas testemunhas de defesa, o mercador Sebastião Pinto, narrou como viera à América no mesmo navio e o conhecia como tratante. Enquanto esteve no porto da erva, por cerca de 
dois meses, encontrou pelo menos duas vezes moradores de São Paulo que chegavam ali para fazer negócios.

Pinheiro foi preso em Assunção, numa casa onde havia se instalado, e seus bens foram inventariados. Sobre ele pairava a acusação de ter passado cem escravos negros clandestinos pela via e alguma quantidade de ouro. Essas acusações não se comprovaram, mas os bens efetivamente arrolados - infelizmente uma parte pequena do documento está ilegível - nos dão uma interessante amostra dos objetos circulantes por esses espaços coloniais.

Parte dos objetos de Manoel Pinheiro poderiam ser de uso pessoal, mas em sendo um tratante, a fronteira entre bens de uso privado e de comércio fica bastante borrada. De todo modo, ali aparecem desde 18 cestas de erva-mate e sete barris vazios, até objetos únicos, como um arcabuz, uma espada, uma taça de prata, uma sela, um prato da China, uma navalha com pedra de amolar, um espelho, uma panela; um pequeno e um grande cofre, ambos de Flandres; e um relógio de sol. Encontramos também alguns objetos peculiares e pouco funcionais em Assunção, como uma carta de marear, um astrolábio, balhestilha e compassos. Pinheiro ainda tinha algum papel em branco, um livro de Regimento, provavelmente o mineral de 1603; um livro de Memória, certamente para controle das dívidas; um livro bastante "popular" no período, o Contentus Mundi do Frei Luis de Granada; um livro de sermões, um "diurno", para orações, e um somente identificado como Paraíso. Por fim, o grosso de sua mercadoria era composto de tecidos variados, como mantas, sete varas de Ruão, ${ }^{51}$ seis barris de tecido caseiro, duas varas de picote, ${ }^{52}$ duas varas de guardanapo, três panos de jubón, ${ }^{53}$ fios variados e fios da Índia. Aparecem ainda, arrolados, seis medalhas de vidro, balanças de peso, facas e tesouras. Em sua defesa, Pinheiro dizia que tudo que ele levava era de uso pessoal, que não era tratante e, portanto, não transportava mercadoria proibida. Segundo ele, as facas e tesouras tinham a função de servir de resgate com os índios do caminho, que the garantiriam livre trânsito, comida, abrigo e guias. Ainda em 1612, Manoel Pinheiro andava pelo Paraguai envolvido com o negócio da erva-mate. ${ }^{54}$

segundo processo foi movido contra o português Manoel Rodrigues, preso em Assunção em 1620 por ter entrado na região pela via proibida de São Paulo. Rodrigues foi preso conjuntamente com um frade franciscano chamado João Gabriel; um português de Beja, chamado Antonio Monteiro, e um outro homem chamado Francisco Mendes Cardoso, português, sem ofício, de 27 anos. Todos teriam vindo juntos de São Paulo. O clérigo conseguiu fugir da cidade, mas Cardoso, que também fora preso, testemunhou dizendo que toda a mercadoria apreendida pertencia à Manoel e que ela já havia sido entregue a ele ainda em São Paulo. Manoel dizia que tudo pertencia ao frei fugido. A carga era muito menos opulenta e diversificada. Era composta por 50 varas de tecido de raxeta, ${ }^{55}$ dez varas de Ruão, 350 fios de lã, 65 facas e tesouras. Rodrigues foi, na ocasião, afiançado por um morador de Assunção, Francisco Vallejo, e se evadiu rumo ao "Peru". 56
51. "Pano de linho tosado e por vezes, tingido, que servia para forrar vestidos. Tecido proveniente de Rouen." Costa (2004, p. 156).

52. "Pano grosseiro, mais conhecido por picoto. Tecido de lã de ovelha, usado para vestimentas de pobres e religiosos. Também podia ser feito de lã de cabra. Espécie de seda muito lustrosa, de que se faziam vestidos." Costa (2004, p. 154).

53. Em português, gibão. Vestimenta que cobria o corpo dos ombros até a cintura, e ajustada ao corpo.

54. ANA (Seção Civil y Judicial, vol. 1946, n. 7 , ano 1612).

55. "Espécie de tecido ordinário, de lã." Costa (2004, p. 156).

56. ANA (Seção Civil y Judicial, vol. 1800, n. 3). 
57. ANA (Seção Historia, vol. 36, n. 23, s.d.). Esse documento foi publicado em Bandeirantes...(1949).

58. Dabbs (1959).

59. Provavelmente trata-se de valón, uma vestimenta de diversos formatos e produzidos a partir de variados tecidos e que se usa em torno do pescoço

60. Baeta, em português. "Tecido de lã, grosseiro e felpudo. Tecido grosso de algodão." Costa (2004, p. 139).

61. Bertangil: "Tecido de algodão que se usava, antigamente, na África e na Ásia. Pano de algodão, azul, preto ou vermelho, produzido pelos cafres." Costa (2004, p. 140).
Por fim, o terceiro processo é de 1621. Nele, o capitão Juan Barba de Añasco e seus soldados interceptaram um grupo de cinco homens que haviam entrado pela via proibida. A prisão se dá em pleno sertão, no Guairá, próximo a reduções jesuíticas e pueblos indígenas do Paranapanema. Depois da prisão, as mercadorias foram leiloadas entre os próprios soldados e os prisioneiros enviados de volta pelo mesmo caminho. Ao longo da leitura do documento percebe-se uma rede de interesses e apropriações, o que faria render um segundo processo, aberto alguns anos depois a pedido do governador do Paraguai, Manoel de Frias, somente para apurar o destino das mercadorias, especialmente um misterioso objeto de ouro.

Os cinco sujeitos são identificados como Miguel Moxica Maldonado, canarino de 30 anos, segundo ele mesmo "hijo de algo notório y no de los prohibidos de passar a las Indias"; Antonio Dutra, português de 28 anos; Diego Vaz, português de 30 anos; Manoel Azevedo, português de 27 anos que passara antes pelo Rio de Janeiro; e Gaspar Fernandes, também português, que viera da Bahia. Todos alegaram não saber que era proibido entrar com mercadoria pelo caminho, e um dos testemunhos chega a dizer que o próprio governador paraguaio, Frias, dissera que todos passavam pela via sem problemas. ${ }^{57} \mathrm{~A}$ alegação fazia sentido, visto que Manoel de Frias, nomeado governador do Paraguai, homem com longa trajetória pelos espaços platinos, desde 1617 andava pela Espanha pleiteando licenças comerciais para Buenos Aires e Assunção. No final de 1620, ancorara em Santos na companhia do capitão-mor da Capitania de São Vicente e parte da poderosa família Sá do Rio de Janeiro, Martim de Sá. ${ }^{58}$

A carga dos "clandestinos" estava distribuída de maneira desigual entre os cinco. Miguel Moxica levava consigo duas escravas de Angola bem jovens e uma indígena; um pequeno vaso de prata, uma caixa com amolador, uma frasqueira com os frascos, cinco tesouras e três facas; uma quantidade boa de shaquiras (contas) e tecidos: quatro lençóis, ligas de tafetá coloridas com fios e presilhas de ouro, sayo jubón (vestido de gibão), vestido de pano, capa balón, 59 colete de armas, tecidos brancos, camisas e panos variados, toalhas de mesa, panos de mãos, meias de seda e algodão, e 50 varas de tecido em rolo. Dutra levava consigo uma adaga, uma espada e uma escopeta, meia libra de pólvora e bastante contaria. Além disso, ampla variedade de tecidos: um chapéu negro, uma toalha, três camisas, toalhas de mesa, meias de lã e seda, uma capa de bayeta, 60 um vestido com o jubón, capa e sayo (vestido), quatro varas de pano pardo, duas varas de Ruão, quatro varas de tecido não identificado, quatro varas de tafetá, três varas de tafetá listrado, cinco varas de bertangi|kl e 24 botões de seda. Diego Vaz carregava somente alguns panos, camisas, um vestido de pano, algumas meias usadas e sapatos. Manoel Azevedo tinha seis pentes de madeira, quatro caixas de facas, um pequeno cofre de Flandres e vasta contaria, identificada como abalorios. Os tecidos que trazia eram básicos e provavelmente de uso pessoal, como um balón velho, meias de lã, duas camisas, cintas e uma faixa. Por fim, Gaspar Fernandes trazia meio maço de shaquiras, cinco facas e alguns 
tecidos, como um balón e uma roupa de pano, um gibão, meias e ligas, duas camisas, panos não identificados, 16 varas de fitas de seda e dois cuellos. ${ }^{62}$

Analisar esses objetos em bloco exige uma primeira classificação, mesmo que bastante imprecisa. Ali estão reunidos bens de uso pessoal, mercadorias de resgate com os índios e de venda e troca nos circuitos locais. De fato, o grosso das mercadorias era composto por tecidos, vestidos e adereços. A quase totalidade é de qualidade inferior ou mais simples, como as varas de Ruão, um pano de linho usado sobretudo para forrar vestidos; as muitas varas de raxeta, um tecido ordinário de lã; ou as varas de picote, um pano grosseiro também de lã; as varas de tafetá; as de bocassin, tecido de algodão usado para forrar tapeçaria; e os barris de tecido chamado de caseiro, muito provavelmente panos de algodão tecidos nas residências da região pelos indígenas Guarani. Há muita fita de seda, fios de lã e da Índia e botões de seda. Alguns gibões de algodão, capas de bayeta (lã), ligas de tafetá; meias de algodão, lã e seda - algumas delas usadas -, camisas; toalhas de mesa, sapatos, borzeguins (um tipo de sapato), guardanapos e chapéus. Compõem, sem dúvida, uma multiplicidade bastante representativa do vestuário dessa sociedade colonial do interior da América espanhola, marcada fortemente pela economia de recursos.

Um segundo universo importante de bens pode ser avaliado pela sua função de resgate e troca com os indígenas. As facas, tesouras, pentes de madeira (caixas), medalhas de vidro, shaquiras e abalorios (contas para pulseiras, colares e adornos variados), alguns tecidos e mesmo as fitas de seda, serviam não só aos mercados coloniais, mas também à população indígena que é onipresente em todas as realidades espaciais dessa sociedade. Estão nas vilas, nas cidades, nos pueblos, nas reduções, nos caminhos. Remam as canoas e balsas, carregam as mercadorias e bagagens, extraem e beneficiam a erva-mate, cultivam a terra, tecem os panos caseiros, atuam nos ambientes domésticos, são disputados por bandeirantes, jesuítas e encomenderos. Guiam os viajantes pelos caminhos e (des) caminhos. Ofereciam aliança ou rivalidade. Enfim, parte importante de qualquer carregamento de mercadorias deveria atender a essa população múltipla e essencial dos espaços coloniais americanos. ${ }^{63}$ É claro que a demanda por esses objetos, por parte das diversas populações indígenas naquela espacialidade, alterava o regime de valor dessas mercadorias. Ao transcenderem fronteiras culturais por meio do fluxo, os objetos escapavam de uma zona mais confortável de valor e adquiriam novos sentidos e novos valores. ${ }^{64}$ Ademais, seu intercâmbio costurava relações sociais e, claro, consolidava hierarquias.

Um outro universo de bens era composto por objetos esparsos e singulares, como frasqueiras com frascos e estojos cirúrgicos, cofres de Flandres de tamanhos variados, vasos e taças de prata; prato da China, papel e pólvora, armamentos como espadas, adagas e arcabuzes e livros.

Dentre os bens que nem sempre eram arrolados nos inventários, mas eram motivo de indagações e suspeitas, estavam os objetos em ouro. Para além das ligas com fechos e fios feitos no metal, na apuração do destino dos bens de
62. Cuello é um adorno de tecido colocado em torno do pescoço.

63. O jesuíta Antonio Ruiz de Montoya (1996, p. 253) descreve os chamados pumberos, índios que trocavam outros índios capturados por vestidos, machados e facas. Formavam, segundo ele, uma "aduana e mesa de cambio” em pleno sertão.

64. Appadurai (2009). 
65. Reis (2013); Revista... (2016).

66. Garavaglia (2008).

67. No porto de Mbaracayú, 2000 libras de erva-mate valiam um vestido (sem que possamos precisá-lo) e 500 libras compravam um chapéu. Gadelha (1980). A noção das relações de troca se estabeleceu a partir de equivalências (trocas diretas), ou mediadas pelo uso de algum tipo de moeda ou mesmo de dinheiro (papel ou metálico). Polanyi (2012).
Miguel de Moxica e dos portugueses que o acompanhavam estava a preocupação com um objeto de ouro. Além disso, anéis e brincos no metal aurífero foram apropriados pelo capitão, conforme se depreende de processo posterior. No outro documento, a suspeita que recaía sobre Manoel Pinheiro era a de que, além de escravos negros, ele também estaria contrabandeando ouro. Essa preocupação tinha sua pertinência. Nos arredores da vila de São Paulo, desde o final do século XVI, lavras do minério estavam sendo exploradas. Apesar de ser de difícil aferição, já que grande parte do metal extraído deveria ser sonegado, pode-se deduzir por relatos desde o século XVI até o XIX, pela presença de objetos de ouro em diversos inventários paulistas, pela permanência do governador-geral do Brasil em São Paulo por alguns anos, por vestígios de obras hidráulicas ainda presentes e por pistas fragmentárias em documentação que uma quantidade razoável deve ter sido retirada dos ribeirões, rios e barrancos paulistas. Um dos responsáveis por isso foi, inclusive, Manoel Pinheiro Azurara, mineiro-mor que descambou para o Paraguai. ${ }^{65}$

Para finalizar os arrolamentos, citamos a erva-mate, mercadoria de enorme importância regional. Para uma certa historiografia, foi o produto que engatou a economia paraguaia no chamado espaço peruano. ${ }^{66}$ Permitia a articulação da pobre e periférica economia regional ao eixo mais dinâmico de circulação mercantil. Extraída naturalmente dos montes de Mbaracayú, foi no início do século XVII que a planta, depois de vencer iniciais resistências dos jesuítas e do todo-poderoso governador Hernandarias de Saavedra, tornou-se mercadoria de alcance amplo. Seus preços duplicavam quanto mais distante estivesse do Guairá. Juntamente com a folha de coca, era um dos únicos produtos de exploração intensiva que não se voltava para o mercado externo, mas era essencialmente dirigido à população indígena que a utilizava tanto para aliviar as agruras do trabalho compulsório a que era submetida, quanto para práticas de sociabilidade, ritualística e farmácia. Ela era colhida, desidratada, torrada e moída pelos índios encomendados e mitayos, explorados sob as mais difíceis condições. Era transportada em cestos e carregada pelas balsas que percorriam a teia de rios da região platina. A erva era, juntamente com a cunha de ferro e o pano de algodão, importante intermediário de relações de troca, tanto na forma de equivalência direta, quanto cumprindo a função de moeda em inúmeras circunstâncias. ${ }^{67}$ Em torno de seu porto, mercadores e tratantes faziam trocas de escravos, roupas e objetos variados. Até mesmo o pagamento da mita era feito com a erva-mate. O ponto nevrálgico do sistema de trocas estabelecidos naquele espaço sem dúvida era o porto de Mbaracayú. Além de centro de embarque da erva, articulava as diversas regiões através de seus rios e caminhos. Por ele passavam - e ficaram - pessoas e objetos.

Os sentidos das coisas

Inicialmente, coloquemos as mercadorias transportadas pelo caminho proibido de São Paulo em perspectiva comparada com outras cargas arroladas na 
região. A caravela Nossa Senhora da Graça, que partiu da Bahia em direção a Buenos Aires em julho de 1599, levava, além do açúcar, mercadoria fundamental da lógica econômica atlântica, tecidos de Ruão, raxetas, tecidos de Holanda, ${ }^{68}$ pentes de marfim, gargantilhas, tesouras (descriminadas entre as de mulher e as de barbear), fitarias, louça, facas de resgate, machados, esporas, enxadas, cadeados de Portugal, ferraduras, castiçais, papéis, "lápis de Valência" e pedra-pomes. Um universo material muito semelhante às cargas apreendidas dos tratantes e aqui apresentadas. Ressalve-se, contudo, que é possível perceber algum grau de sofisticação maior na carga direcionada a Buenos Aires e que teria, muito provavelmente, o destino de circulação pelos interiores do Caminho Real de Potosí: facas de marfim, louças e gargantilhas exemplificam isso. ${ }^{69}$ De todo modo, concordamos com Braudel quando ele afirma que "distinguir entre luxo e miséria é apenas uma primeira classificação, monótona, por si só pouco precisa". 70 Isso porque torna absolutos os valores das mercadorias, retirando-as de uma análise mais contextual.

Dois mercadores portugueses presos em Santa Fé por cobrarem preços abusivos e comercializarem "livros de heresia" tinham, como carga principal: forros de tafetá, tecidos de Ruão e raxetas. Além disso, vendiam sombreros de Tucumã ${ }^{71}$ Os mesmos tecidos de tafetá e raxetas podem ser encontrados, por exemplo, no dote de Maria Dorantes, filha de Luis Dorantes, regidor de Assunção no começo do século XVII. ${ }^{72}$ Na carga que Antonio Correa de Sá mandou trazer de Santa Fé até Assunção, além de açúcar e sebo derretido, encontram-se varas de algodão, tafetá e tecidos de Holanda.

A presença dessas mercadorias - especialmente os tecidos - em diversas circunstâncias e caminhos denota o quanto representavam objetos comuns naquele espaço regional. Eles aparecem sendo trocados comercialmente - diretamente ou intermediados por moeda -,73 entregues em dote, legados em testamentos, utilizados para suborno, pagamentos variados e resgates com indígenas, desde os caminhos atlânticos até os potosinos. A diferença talvez estivesse num universo mais rústico e menos volumoso das mercadorias comercializadas pela via de São Paulo rumo ao Paraguai.

Entretanto, tal universo de mercadorias participa, sem dúvida, de uma economia-mundo cada vez mais verdadeiramente global, passível de trocas interoceânicas e inter-regionais, e que se reflete em maior ou menor escala na realidade material dos contemporâneos dos séculos XVI e XVII. A análise do recorte espacial que fizemos, particular, revela a existência de louça da China, fios da Índia, cofres de Flandres, tecidos de Ruão e Holanda, por exemplo, que dão materialidade a essa troca e intercâmbio articulados, nesse momento e especialmente, pelos impérios ibéricos e sua atuação nas quatro partes do mundo. De fato, as redes comerciais e os circuitos mercantis desenham um sistema que funciona interligado, conectando mercadorias de variadas origens e alcances nas mesmas bagagens. Dessa forma, as cargas de nossos tratantes reúnem bens de caráter global, digamos assim, com outros "regionais". Ao lado do fio da Índia e
68. "Tecido de linho muito fino e fechado ou tapado, que se fabrica na Holanda. Havia holandas finas, ordinárias, grossas, frisadas, riscadas, largas e por vezes, produzidas com seda." Costa (2004, p. 149).

69. ANA (Seção Civil y Judicial, vol 1599, n. 6).

70. Braudel (1995, p. 300301).

71. ANA (Seção Civil y Judicial, vol. 1439, n. 2, ano 1600).

72. ANA (Seção Nova Encadernação, vol. 19, n. 82, s.d.).

73. Era manifesta a ausência de dinheiro efetivo na governação do Paraguai. As trocas eram feitas diretamente ou com moedas locais (erva-mate, tecido, cunhas de ferro), mas a "semântica" proporcionada pelo dinheiro mesmo assim balizava e quantificava grande parte das relações mercantis. 
74. Não empreendemos uma análise da procedência de diversos tecidos, mas algumas pesquisas têm indicado a abundante presença de têxteis chineses nos mercados americanos do século XVII, - inclusive platinos - $\mathrm{e}$ vindos principalmente através do Galeão das Filipinas. Bonialian (2016).

75. Polanyi (2012).

76. Pensamos aqui num objeto - tecido - que atua no sentido de qualificar o sujeito socialmente, numa relação que nunca é estável, mas marcada pelas interações e contextos específicos. Meneses (1998). $\mathrm{Na}$ análise empreendida neste texto, ficamos restritos à lógica da circulação mercantil dos têxteis, mas é fundamental compreender que as roupas são o resultado de processos produtivos e que participam de uma "linguagem" dos trajes que define em grande parte seu consumo. Roche (2000).

77. Citamos, como exemplo, o português Felipe Nunes, um dos soldados da tropa de Añasco, que negociava erva-mate em Mbacarayú. Ele tinha uma neta em São Paulo e morreu no "caminho proibido” em 1636. do tecido de Ruão, aparece a erva-mate, os sombreros de Tucumã, o sebo derretido e os panos caseros produzidos no próprio Paraguai. ${ }^{74}$

Um segundo aspecto bastante evidente é que a mercadoria mais valiosa e abundante parece ser a composta pelos tecidos, em forma crua ou já transformada em vestuário. A quase onipresença desse objeto em particular nos ajuda a refletir sobre esses bens não só como objetos de estrito valor econômico e de troca mercantil. Claro deve estar, desde sempre, que a própria concepção de comércio que atravessa essas relações é bastante diferente das modernas formas de se ver a atividade comercial. Na linha que já sugerimos no começo deste texto - a de Karl Polanyi -, devemos pensar a atividade mercantil como um universo de relações que ultrapassa as funções meramente comerciais e estritamente econômicas. ${ }^{75}$ As trocas ditas comerciais alimentam relações sociais e são fundamentais na estruturação de alianças, comportamentos e conexões variadas. Além disso, percebe-se como o objeto guarda, além de sua evidente condição material e funcional, sentidos simbólicos e culturalmente atribuídos. Assim, da mesma maneira que o sujeito atua sobre o objeto, o objeto atua sobre o sujeito. No espaço que aqui abordamos, os tecidos e as roupas foram utilizados tanto como bens de valor comercial, suborno, articulação de alianças, resgate, pagamento de guias e moeda, denotando funções e sentidos marcados pela lógica econômica regional, e pelas fronteiras culturais que se articulam naquele cenário colonial. Infelizmente, não pudemos abordar aqui os trajetos dos tecidos, por exemplo, para além de sua situação mercantil, mas podemos e devemos subentender o papel que eles têm para a construção de valores sociais e para visibilizar e organizar hierarquias. ${ }^{76}$

Há, ainda, mais um sentido dos objetos que consideramos importante ressaltar. Para tanto, vejamos novamente o processo contra Miguel Moxica Maldonado, que foi reaberto em 1623 por mandato do governador Frias, e que buscava saber o que fora feito das mercadorias confiscadas. Um dos aspectos mais interessantes dessa reabertura é poder acompanhar o destino de algumas das mercadorias apreendidas, em função dos testemunhos colhidos dois anos depois. Através deles, ficamos sabendo que os frascos, boa parte das contas, shaquiras e abalorios, bem como varas de tecidos mais simples, foram distribuídos entre os vários soldados que participaram da prisão. Os soldados, assim chamados por mera contingência, eram na verdade vecinos ou moradores das vilas do Guairá e possuidores de encomiendas, mais ou menos volumosas, e partícipes dos negócios da erva-mate. Por estarem envolvidos em suas relações cotidianas com os indígenas, esses objetos, chamados vulgarmente "de resgate", cumpririam importante função mediadora em seus tratos..$^{77}$

Os bens considerados mais valiosos nas redes de relações mercantis, como as escravas negras, algumas roupas de tecido mais elaborado, as ligas com fechos e fios de ouro, um colar de ouro, um estojo com instrumentos cirúrgicos, brincos e anéis de ouro ficaram com o capitão Barba de Añasco, consolidando a hierarquia daquela pequena companhia de soldados. Uma faca sem adorno e uma espada com adornos bordados em ouro e prata foram entregues, pelo próprio 
capitão, para um vigário chamado Frei Salgado. $\bigcirc$ padre jesuíta José Citaldini, um dos pioneiros missionários do Guairá, fundador, com Simão Massetta, das reduções de Loreto e Iguaçu, recebeu alguns vestidos. Curiosamente, uma parte deles voltou para as mãos do próprio Moxica. Por fim, um cacique não nomeado recebeu do capitão apenas uma capa com capuz.

Nessa distribuição do "espólio", o sentido se torna evidente. É um articulador de redes de reciprocidade e aliança, numa referência possível ao kula. ${ }^{78}$ Os objetos aqui elencados parecem alimentar, e estruturar, uma rede que era formada pelos diversos agentes daquela sociedade colonial: encomenderos, bandeirantes, padres, jesuítas e indígenas. $\bigcirc$ papel de destaque dos tecidos é grande e eles participam, através da circulação, de forma fundamental da arquitetura de um espaço colonial conectado luso-castelhano. As conexões ajudaram na configuração de uma espacialidade, e a materialidade dessas conexões se fez a partir desses objetos. Na companhia dos sujeitos (entrelaçando-se mutuamente), os objetos, pessoais, de resgate ou de troca, articularam grupos sociais, agentes os mais diversos e territórios coloniais e indígenas. Ganharam sentidos variados conforme as distintas realidades sociais. Foram vetores na configuração desse amplo espaço conectado, que reuniu os objetos, as pessoas e o ambiente.
78. O conceito, surgido através do trabalho de Malinowski, refere os intercâmbios - e as redes de relações derivadas - praticados nas sociedades da Nova Guiné. No caso que aqui trabalhamos, buscamos nos aproximar da perspectiva que compreende a circulação de objetos como "criadora" de sociedades e relações. Appadurai (2009); Miller (2013). 


\section{REFERÊNCIAS}

FONTES MANUSCRITAS

Arquivo General de Indias (AGI)

Fundo Mapas y Planos - Buenos Aires (17, 1,1, s.d.) e Fundo Contaduria (vol. 1690).

Arquivo Nacional de Asunción (ANA)

Seção História (Vol. 36, números 22 e .23)

Seção Civil y Judicial, vols. 1439, 1532, 1549, 1599, 1685, 1800, 1944, 1946.

Seção Nova Encadernação, volumes 19 e. 360, s.d.

FONTES IMPRESSAS

ANAIS do Museu Paulista, São Paulo. Tomo I, 1922.

ATAS da Câmara da Villa de São Paulo. Vol. II. São Paulo: Duprat \& Cia; 1915.

BANDEIRANTES no Paraguai. Século XVII. (Documentos Inéditos). São Paulo: Divisão do Arquivo Histórico/Prefeitura do Município de São Paulo, 1949.

CORTESÃO, Jaime. Jesuítas e bandeirantes no Guairá (1549-1640). Rio de Janeiro: Biblioteca Nacional, 1951.

PETIÇÃO do licenciado Antonio de Leon y Pinelo. Sevilla, [s.d.]. Archivo General de Indias, Charcas, 33.

REGISTRO Geral da Câmara Municipal de São Paulo. Vol. I e II. Séculos XVI e XVII. São Paulo: Typographia Piratininga, 1917.

RUIZ DE MONTOYA, Antonio. La conquista espiritual del Paraguay. Asunción: El Lector, 1996. 
APPADURAI, Arjun (Org.). A vida social das coisas: as mercadorias sob uma perspectiva cultural. Niterói: Eduff, 2009.

ARMEMI, Alberto. Ciudad de Deus y ciudad del sol. El "Estado" jesuíta de los guaraníes (16091768). Ciudad de México: Fondo de Cultura Económica, 1996.

ASSADOURIAN, Carlos Sempat. El sistema de la economia colonial: el mercado interior, regiones y espacio económico. Ciudad de México: Nueva Imagem, 1983.

BONIALIAN, Mariano. La "ropa de la China" desde Filipinas hasta Buenos Aires. Circulación, consumo y lucha corporativa, 1580-1620. Revista de Indias, Madrid: CSIC, v. LXXVI, n. ${ }^{\circ}$ 268, p. 641-672, 2016.

BRAUDEL, Fernand. Civilização material, economia e capitalismo - séculos XV-XVIII. São Paulo: Martins Fontes, 1995 (vol.2: As estruturas do cotidiano).

CANABRAVA, Alice Piffer. O comércio português no rio da Prata: 1580-1640. Belo Horizonte: Itatiaia; São Paulo: Edusp, 1984.

CARDOZO, Ramón. La Antigua Província de Guairá y la Villa Rica del Espíritu Santo. Buenos Aires: Librería y Casa Editora de Jesús Menéndez: 1938.

CAVAlCANTE, Paulo. Negócios de Trapaça. Caminhos e Descaminhos na América Portuguesa (1700-1750). São Paulo: Hucitec, 2006.

COSTA, Manuela Pinto da. Glossário de termos têxteis e afins. Revista da Faculdade de Letras. Ciências e técnicas do património, Porto: Universidade do Porto, I Série, v. III, p. 137-161, 2004.

DABBS, Jack Autrey. Manuel de Frías and rioplatine free trade. Revista de Historia de América, [S.1.]: Pan American Institute of Geography and History, ${ }^{\circ}$ 48, dec. 1959.

FERREIRA, Tito Lívio. O Elemento Espanhol na Capitania de São Vicente. Revista do Instituto Histórico e Geográfico de São Paulo, São Paulo: Instituto Histórico e Geográfico de São Paulo, n. 69, p. 151-166, 1971.

FRANCO, Francisco de Assis Carvalho. Dicionário de bandeirantes e sertanistas do Brasil séculos XVI, XVII, XVIII. São Paulo: Comissão do IV Centenário da Cidade de São Paulo, 1954.

GADELHA, Regina Maria. As missões jesuíticas do Itatim - Estruturas socioeconômicas do Paraguai Colonial: séculos XVI e XVII. Rio de Janeiro: Paz e Terra, 1980.

GARAVAGLIA, Juan Carlos. Mercado interno y economia colonial: tres siglos de historia de la yerba mate. Rosario: Prohistoria ediciones, 2008.

GARCIA, Nilo. A aclamação de Amador Bueno. A influência espanhola em São Paulo. Rio de Janeiro, 1956. Tese (Livre-docência) - Universidade do DF. 
GONZÁLEZ LEBRERO, Rodolfo E. La pequeña aldea: sociedad y economía en Buenos Aires: 1580-1640. Buenos Aires: Biblos, 2002.

GRUZINSKI, Serge. As quatro partes do mundo: história de uma mundialização. Belo Horizonte: Editora UFMG; São Paulo: Edusp, 2014.

HOLANDA, Sérgio Buarque de. Caminhos e fronteiras. São Paulo: Companhia das Letras, 1994. Capítulos de expansão paulista. São Paulo: Companhia das Letras, 2014.

. Expansão paulista em fins do século XVI e princípio do século XVII. Publicações do Instituto de Administração, São Paulo: Ed. Instituto de Administração de Ciências Econômicas e Administração da USP, n. 29, p. 3-23, junho de 1948.

KOPYTOFF, Igor. A biografia cultural das coisas: a mercantilização como processo. In: APPADURAI, Arjun (Org.). A vida social das coisas: as mercadorias sob uma perspectiva cultural. Niterói: Eduff, 2009.

MENESES, Ulpiano Toledo Bezerra de. Memória e Cultura Material: documentos pessoais no espaço público. Estudos Históricos. Rio de Janeiro: CPDOC/FGV, v. 11, n. 21, p. 89-104, 1998.

MILLER, Daniel. Trecos, troços e coisas: estudos antropológicos sobre a cultura material. Trad. Renato Aguiar. Rio de Janeiro: Zahar, 2013.

MORAES, Antonio Carlos Robert. Bases da formação territorial do Brasil: o território colonial brasileiro no longo século XVI. São Paulo: Hucitec, 2000.

MOURA. Gentil Assis de. O caminho do Paraguai a Santo André da Borda do Campo. Revista do Instituto Histórico e Geográfico de São Paulo, São Paulo: Instituto Histórico e Geográfico de São Paulo, tomo 13, 1908.

MOUTOUKIAS, Zacarias. Contrabando y control colonial en el siglo XVII: Buenos Aires, el Atlántico y el Espacio Peruano. Buenos Aires: Centro Editor de América Latina, 1988.

PERUSSET, Macarena. Contrabando y sociedade en el Río de la Plata Colonial. Buenos Aires: Dunken, 2006.

PIJNING, Ernst. Contrabando, ilegalidade e medidas políticas no Rio de Janeiro do século XVIII. Revista Brasileira de História, São Paulo: ANPUH, v. 21, n. 42, p. 397-414, 2001.

POLANYI, Karl. A subsistência do bomem e ensaios correlatos. Rio de Janeiro: Contraponto, 2012.

QUARLERI, Lia. Rebelión y guerra en las fronteras del Plata. Guaraníes, jesuitas e imperios coloniales. Buenos Aires: Fondo de Cultura Económica, 2009.

RAFFESTIN, Claude. Por uma geografia do poder. São Paulo: Ática, 1993.

REDE, Marcelo. Estudos de cultura material: uma vertente francesa. Anais do Museu Paulista. São Paulo, v. 8-9, n. 1, p. 281-291, 2001. 
REIS, Nestor Goulart. As minas de ouro e a formação das Capitanias do Sul. São Paulo: Via das Artes, 2013.

REVISTA DO MUSEU DE ARQUEOLOGIA E ETNOLOGIA DA USP. São Paulo: MAE/USP, n. $26,2016$.

ROCHE, Daniel. História das coisas banais: nascimento do consumo nas sociedades do século XVII ao XIX. Rio de Janeiro: Rocco, 2000.

SANTOS, Milton. A natureza do espaço. Técnica e tempo, razão e emoção. São Paulo: Edusp, 2006.

VENTURA, Maria da Graça Alves Mateus. Portugueses no Peru ao tempo da União Ibérica: mobilidade, cumplicidades e vivências. Lisboa: Imprensa Nacional; Casa da Moeda, 2005. v. I e II.

VILARDAGA, José Carlos. Imagens em trânsito: as virgens de Luján e Sumampa e os circuitos coloniais na América Meridional na primeira metade do século XVII. Anais do Museu Paulista. São Paulo, v. 23, n. 2, p. 43-67, jul.-dez. 2015.

São Paulo no império dos Felipes: conexões na América Meridional: 1580-1640. São Paulo: Editora Intermeios, 2014.

Artigo apresentado em 30/01/2017. Aprovado em 15/03/2017. 